\title{
Meaningful Personalization at a self-service kiosk
}

\author{
Jamie Sands \\ NCR Financial Solutions \\ Group Ltd. \\ 3 Fulton Road \\ Dundee, DD2 4SW, \\ Scotland \\ +44 (0)1382 714045 \\ jamie.sands@ncr.com
}

\author{
Graham Johnson \\ NCR Financial Solutions \\ Group Ltd. \\ 3 Fulton Road \\ Dundee, DD2 4SW, \\ Scotland \\ +44 (0)1382 718321 \\ graham.johnson@ncr.com
}

\author{
Professor David Benyon \\ $\mathrm{HCl}$ Group, Napier \\ University \\ 10 Colinton Road \\ Edinburgh, EH10 5DT, \\ Scotland \\ +44 (0) 1314552736 \\ d.benyon@napier.ac.uk
}

\author{
Dr Gregory Leplatre \\ $\mathrm{HCl}$ Group, Napier \\ University \\ 10 Colinton Road \\ Edinburgh, EH10 5DT, \\ Scotland \\ +44 (0) 1314552709 \\ g.leplatre@napier
}

\begin{abstract}
Personalization of a self-services kiosk or ATM may provide the user with an efficient means of obtaining new appropriate services with the degree of immediate gratification consumers now require. Successful personalization relies on many factors including acceptance of the services provided and the way these services are delivered. This paper presents a summary of the results from a recent investigation of personalized services at a self-service kiosk and the use of avatars as a potential interface style. Results indicate that users - in particular younger users would accept personal information being used and would accept new services such as news headlines and budgeting advice at a self-service kiosk.
\end{abstract}

\section{General Terms}

Experimentation, Security, Human Factors

\section{Keywords}

Personalization, ATM, Public Technology, Security.

\section{INTRODUCTION}

By using personal information, a kiosk may be able to better anticipate and deliver the services the user requires, increasing transaction efficiency, ensuring consumer satisfaction and often creating an improved customer/company relationship [1]. Personal information may also be used to broaden the range of tailored services and bring new services to the users' attention, satisfying the demand for greater functionality and a more effective use of the consumers' time.

Appropriate interface design is a critical aspect of the acceptance of any personalized, public, self-service kiosk to facilitate the speedy, secure, trustworthy and easily understandable acquisition of desired options. The use of personal information in determining applications or menu options may lead to confusion about how resulting options were chosen and what information has been applied. One approach is to use an avatar or companion to change the interaction into a realistic dialogue between the user and the avatar. However, the choice of companion and dialogue style is equally important in

(C) Sands, J., Johnson, G., Benyon, D and Leplatre, G., 2007 Published by the British Computer Society Volume 2 Proceedings of the 21st BCS HCI Group Conference

HCI 2007, 3-7 September 2007, Lancaster University, UK Devina Ramduny-Ellis \& Dorothy Rachovides (Editors) matching the expectation of the consumer's experience.

Reeves and Nass [3] suggest that human-computer interaction is akin to normal social interaction. In simple terms, same social rules apply, and users will react to a personified computer as they would a real person, similarly they have expectations about how the computer will behave because of the expected social rules. In the example of a bank teller, a formal and business like interaction would therefore be expected for both a human bank teller and a cash dispensing ATM. However this theory does not take into account the use of personal information. Simple withdrawals, either from the ATM or teller are impersonal (other than a courteous smile), but (hypothetically) a teller offering insurance for their holiday (because they are aware a holiday has been purchased) may not expect such an impersonal dialogue. The appropriate level of dialogue is unclear.

Previous work has investigated alternative interface styles using an informal companion - 'Granny' interface offering personalized informal assistance and services and comparing these with an existing formal ATM interface and a real cashier [4]. interface delivered instruction and advice as a real Granny may do, offering personal reminders about bills, important dates, local information and even horoscope information. Results indicated that 'Granny' was perceived primarily in terms of social and aesthetic values where as the ATM and real cashier was considered in terms of function.

The perceived personality of an interface is also influenced by the tone of the dialogue used in the interaction. A perceived formal interface may be influenced not only by the look of the interface, but also the way in which instructions and communication is conducted. A recent study [5] investigated users perceptions of the tone of dialogue (TOD) used by a virtual ATM while offering a range of unfamiliar services including a train booking service and share trading. Results showed that users rated the importance of TOD significantly higher than their awareness of it. Users also rated their preference for a brief tone highest followed by instructional and re-assuring with a personal tone least desired. The results indicate that even for new services, consumers' reluctance to waste time is paramount; however formal instructional and reassuring information is also necessary for new services. A personal/informal style appears to be least accepted dialogue style.

The acceptance of personal information in order to provide new services is not solely linked to the way in which the services are provided to the user. Many consumers are reluctant to allow personal information to be used for a number of reasons, primarily over concerns about security through an increased 
risk of putting sensitive information at risk and through a mistrust of how information will be used and who will be in control of its use [6] and a reluctance to spend the time setting up or providing personal information [7]. However personal information can also be used to improve accessibility [8] and provide the individual with tailored appropriate services. One particular study [9] investigated consumer's opinions of selfservice kiosks and ATMs and examined consumer's opinions of financial and e-commerce services that could be conducted through a self service kiosk. Personalization has the potential to benefit the consumer in more ways than a greater customer/business relationship. Through knowledge of the user, the system can offer tailored services, recommend products, remind users of important events and even give advice about the users financial behaviors. Conceivably personal information can also be used to improve security, as personal information is particular to each user. Using personal information can be a quick and memorable way of verifying a user's identity.

\section{METHOD}

To investigate users' opinion of the use of personal information, new services, security and novel interface styles a prototype self-service kiosk was developed. The prototype was run from a laptop and displayed using a touchscreen interface. The laptop and touchscreen was incorporated into a purpose built kiosk, allowing the set-up to appear like a real self-service kiosk. The aim of the investigation was to implement new services and features, seamlessly into a transaction, using personal information to drive information, new services and security of the transaction.

Participants were asked to perform a number of transactions using a self-service kiosk. The investigation looked at users' perception of five new services that could be offered at an ATM type kiosk: budgeting advice; on-line product purchases; EBay ${ }^{\mathrm{TM}}$ auctions; restaurant booking services; and news headlines. These services were personalized through the application of user information. Prior to the start of each test, participants were asked to provide some personal information in the form of favorite music and film genres, food and interest in current affairs and sport. This was done using the touchscreen interface. This information was used to generate appropriate news headlines and as a method of identity verification where participants were identified by selecting the correct option from a menu to authorize certain additional services.

(a)

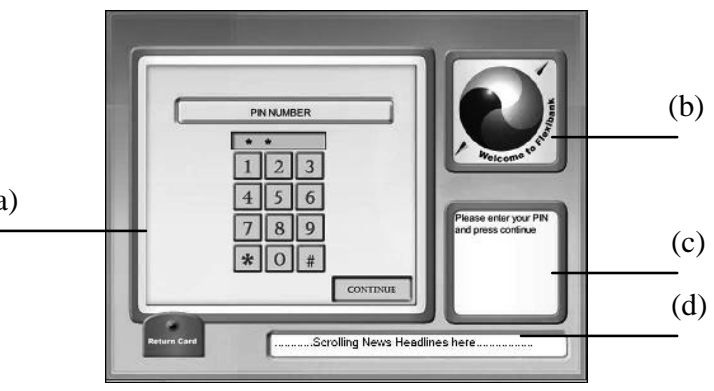

Figure 1. Example of non-avatar interface used (a) transaction pane, (b) logo/avatar pane (replaced with avatars in the avatar conditions, (c) instruction pane and (d) scrolling news headline bar.

Three different interface designs were used. The overall interface is shown in Figure 1. In the avatar conditions, pane (b) was replaced by either the formal avatar (Figure 2 (a) or the informal avatar (Figure 2 (b)).
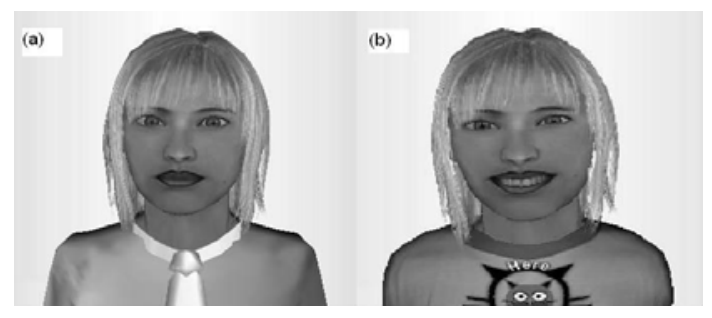

Figure 2. Examples of avatar conditions, (a) formal avatar and (b) informal avatar

The avatar conditions audibly spoke the written transaction instructions to the user. The formal avatar used the same formal instructional dialogue as used in the non-avatar condition, whereas the informal avatar referred to themselves in the first person and provided more informal instructions. Examples of the formal and informal dialogue can be seen below.

\begin{tabular}{|l|l|}
\hline Style & \multicolumn{1}{|c|}{ Example } \\
\hline Formal & $\begin{array}{l}\text { 'Your account has been debited successfully, would; } \\
\text { you like to perform any other services? }\end{array}$ \\
\hline Informal & $\begin{array}{l}\text { 'I have debited your account; can I help you with } \\
\text { anything else?' }\end{array}$ \\
\hline
\end{tabular}

Each experiment session included pre-test instructions and information gathering session, three transactions and a posttest online questionnaire evaluation. Each test took approximately twenty minutes to complete.

A within subject design was used, whereby all participants performed all of the tasks. After performing each of the tasks, participants were asked to rate their level of agreement with statements using 5-point Likert scales (Agree (A), Slightly agree (SA), undecided (U), slightly disagree (SD) and disagree (D)). New services were addressed in terms of usefulness, appropriateness and their willingness to use and accept the service. Evaluation of the interfaces focus on statements regarding people's perception of characteristics of the interface (see Table 3).

Each task was preceded by a written scenario. For example one scenario required the user to withdraw $£ 40$ to go out for the evening, but when they tried to do this a budgeting service interrupted saying that it was recommended to withdraw only $£ 30$. Another scenario required them to check their account balance. This was accompanied by a news headline concerning their favourite football team. In this way personalization and new services were combined and presented through each of three interfaces. The first task included an online purchase, the second an EBay ${ }^{\mathrm{TM}}$ auction and the third was a restaurant booking service. After completing the tasks, users completed the online evaluation designed using QuestionPro on a laptop computer (www.questionpro.com). Responses were automatically saved anonymously online.

\section{RESULTS}

For all results percentages have been rounded up to the nearest round figure. Acceptance is defined as a combined measure of usefulness, appropriateness and willingness. 54 volunteer participants were recruited from the staff, student and visitors to Napier University where the experiment took place. $65 \%$ were male, $45 \%$ were aged $25-34,22 \%$ were younger and $33 \%$ older; 28\% visited an ATM once a week and 48\% 2-3 times a week. New services are presented in Table 1. 
Table 1. Level of acceptance for each new service

\begin{tabular}{|c|c|c|c|c|c|}
\hline & A & SA & $\mathrm{U}$ & $\mathrm{SD}$ & $\mathrm{D}$ \\
\hline \multirow{2}{*}{ News Headlines } & $22 \%$ & $30 \%$ & $6 \%$ & $4 \%$ & $38 \%$ \\
\hline & \multicolumn{2}{|c|}{$52 \%$} & $6 \%$ & \multicolumn{2}{|c|}{$42 \%$} \\
\hline \multirow{2}{*}{ EBay $^{\mathrm{TM}}$} & $11 \%$ & $19 \%$ & $16 \%$ & $10 \%$ & $44 \%$ \\
\hline & \multicolumn{2}{|c|}{$30 \%$} & $16 \%$ & \multicolumn{2}{|c|}{$54 \%$} \\
\hline \multirow{2}{*}{ Online Purchases } & $15 \%$ & $24 \%$ & $19 \%$ & $11 \%$ & $31 \%$ \\
\hline & \multicolumn{2}{|c|}{$40 \%$} & $19 \%$ & \multicolumn{2}{|c|}{$41 \%$} \\
\hline \multirow{2}{*}{ Restaurant booking } & $19 \%$ & $20 \%$ & $12 \%$ & $15 \%$ & $34 \%$ \\
\hline & \multicolumn{2}{|c|}{$39 \%$} & $12 \%$ & \multicolumn{2}{|c|}{$49 \%$} \\
\hline \multirow{2}{*}{ Budgeting advice } & $53 \%$ & $27 \%$ & $8 \%$ & $4 \%$ & $8 \%$ \\
\hline & \multicolumn{2}{|c|}{$80 \%$} & $8 \%$ & \multicolumn{2}{|c|}{$12 \%$} \\
\hline
\end{tabular}

Three main results can be obtained from table 1 above. Budgeting advice is highly accepted with $80 \%$ of participants in favour. For most services (budgeting advice aside) there is almost a 50/50 split between those accepting and rejecting all services, no service has more than $19 \%$ of undecided participants. These results suggest that users would like to see budgeting advice at the self-service kiosk, however the population is split between accepting and rejecting other services, those who would accept them do not feel as strongly about accepting them. Participant's perception of the use of personal information is summarized in table 2 .

The results in table 2 show that only $28 \%$ of participants did not think personal information should be used to provide enhanced services at the self-service kiosk where as $63 \%$ of participants saw the use of personal information as a means of increasing security at the self-service kiosk. These results suggest that not only is it acceptable for personal information to be used to provide additional services, but it can also be used to provide increased security measures.

Table 3. User perceptions towards the interface styles used

\begin{tabular}{|c|c|c|c|c|}
\hline \multirow{3}{*}{$\begin{array}{l}\text { I felt in } \\
\text { control of } \\
\text { this interface }\end{array}$} & A\&SA & $85 \%$ & $74 \%$ & $74 \%$ \\
\hline & $\mathrm{U}$ & $6 \%$ & $7 \%$ & $9 \%$ \\
\hline & SD\&D & $9 \%$ & $19 \%$ & $17 \%$ \\
\hline \multirow{3}{*}{$\begin{array}{l}\text { This interface } \\
\text { is appropriate }\end{array}$} & A\&SA & 91\% & $52 \%$ & $52 \%$ \\
\hline & $\mathrm{U}$ & $2 \%$ & $17 \%$ & $17 \%$ \\
\hline & SD\&D & $7 \%$ & $31 \%$ & $31 \%$ \\
\hline \multirow{3}{*}{$\begin{array}{l}\text { I could trust } \\
\text { this interface }\end{array}$} & A\&SA & $91 \%$ & $63 \%$ & $56 \%$ \\
\hline & $\mathrm{U}$ & $5 \%$ & $14 \%$ & $18 \%$ \\
\hline & SD\&D & $4 \%$ & $22 \%$ & $26 \%$ \\
\hline \multirow{3}{*}{$\begin{array}{l}\text { I felt this } \\
\text { condition } \\
\text { was secure }\end{array}$} & A\&SA & $\mathbf{8 0 \%}$ & $54 \%$ & $52 \%$ \\
\hline & $\mathrm{U}$ & $15 \%$ & $19 \%$ & $17 \%$ \\
\hline & SD\&D & $6 \%$ & $28 \%$ & $31 \%$ \\
\hline \multirow{3}{*}{$\begin{array}{l}\text { I would use } \\
\text { this interface }\end{array}$} & A\&SA & $90 \%$ & $39 \%$ & $43 \%$ \\
\hline & $\mathrm{U}$ & $5 \%$ & $17 \%$ & $16 \%$ \\
\hline & SD\&D & $5 \%$ & $44 \%$ & $41 \%$ \\
\hline \multirow{3}{*}{$\begin{array}{l}\text { This interface } \\
\text { was Formal }\end{array}$} & A\&SA & $72 \%$ & $52 \%$ & $18 \%$ \\
\hline & $\mathrm{U}$ & $24 \%$ & $37 \%$ & $28 \%$ \\
\hline & SD\&D & $4 \%$ & $11 \%$ & $54 \%$ \\
\hline \multirow{3}{*}{$\begin{array}{l}\text { This interface } \\
\text { was Personal }\end{array}$} & A\&SA & $43 \%$ & $54 \%$ & $60 \%$ \\
\hline & $\mathrm{U}$ & $39 \%$ & $28 \%$ & $25 \%$ \\
\hline & SD\&D & $18 \%$ & $18 \%$ & $15 \%$ \\
\hline Most suitable & & $76 \%$ & $9 \%$ & $15 \%$ \\
\hline Preferred & & $67 \%$ & $5 \%$ & $28 \%$ \\
\hline
\end{tabular}

Table 3 shows that most participants consider all the interfaced designs to provide a high level of control and are appropriate, trustworthy and secure; however the non-avatar interface is consistently rated higher on all of these factors

Table 2. Level of acceptance of the use of personal information and perceived benefit to security

\begin{tabular}{|c|c|c|c|c|c|}
\hline & A & SA & U & SD & D \\
\hline \multirow{2}{*}{$\begin{array}{l}\text { Personal information is } \\
\text { ok to be used }\end{array}$} & $22 \%$ & $26 \%$ & $24 \%$ & $13 \%$ & $15 \%$ \\
\hline & \multicolumn{2}{|c|}{$48 \%$} & $24 \%$ & \multicolumn{2}{|c|}{$28 \%$} \\
\hline \multirow{2}{*}{$\begin{array}{l}\text { Personal information } \\
\text { increases security }\end{array}$} & $22 \%$ & $41 \%$ & $22 \%$ & $7 \%$ & $7 \%$ \\
\hline & \multicolumn{2}{|c|}{$63 \%$} & $22 \%$ & \multicolumn{2}{|c|}{$14 \%$} \\
\hline
\end{tabular}

The non-avatar interface is considered the most likely to be used interface with almost $90 \%$ agreement, with avatar conditions gaining around $40 \%$ acceptance. Further investigation showed that when comparing interfaces, the nonavatar interface is considered both most suitable and most preferred, interestingly the informal avatar in considered higher on ratings of suitability and preference to the formal avatar condition. These results suggest that when using avatar conditions, users perceive an element of control, trust and security to be lost, although not completely. Users prefer to use interfaces without avatars at the self-service kiosk when using personal information, however if an avatar condition was to be employed, an informal personality would be better received than a formal avatar.

To further investigate differences between identified groups, Spearman's non-parametric correlations were performed to investigate for connections between factors. Statistical significance levels are indicated as (..) significant to 0.01 , and (.) significant to $0.05,2$ tailed.

Table 4. Correlation relationships between age and new services

\begin{tabular}{|l|c|c|c|c|}
\hline & \multicolumn{4}{|c|}{ Age } \\
\hline & Useful & Appropriate & $\begin{array}{c}\text { Would } \\
\text { Use }\end{array}$ & $\begin{array}{c}\text { Would } \\
\text { accept }\end{array}$ \\
\hline News Headlines &.$\cdot$ &.$\cdot$ &.$\cdot$ & $\mathrm{n} / \mathrm{a}$ \\
\hline EBay ${ }^{\mathrm{TM}}$ & $\cdot$ & & $\cdot$ & $\mathrm{n} / \mathrm{a}$ \\
\hline Online purchases & & & & $\mathrm{n} / \mathrm{a}$ \\
\hline $\begin{array}{l}\text { Restaurant } \\
\text { booking }\end{array}$ &.$\cdot$ & $\cdot$ & & $\mathrm{n} / \mathrm{a}$ \\
\hline Budgeting advice &.$\cdot$ & &.$\cdot$ & \\
\hline
\end{tabular}

Table 4 shows that age is significantly correlated with many aspects of new services; most notably age is correlated with the acceptance of news headlines and budgeting advice. Examination of the correlations shows that as user get older they are less likely to accept the services indicated above. Frequency of ATM use did not correlate with any new services or perceptions of the use of personal information.

Table 5 shows significant correlations for each service and its associations with other services. It can be seen that almost all services significantly correlate with each other. Suggesting that acceptance of one service is indicative of a tendency to accepting other services. Only user intention to use a News 
headline service is not significantly indicative of user acceptance of a restaurant booking service.

Table 5. Correlation relationships between participants' perceptions of each new service

\begin{tabular}{|c|c|c|c|c|c|c|c|c|c|c|c|c|c|}
\hline & & \multicolumn{3}{|c|}{ News } & \multicolumn{3}{|c|}{ EBay $^{\mathrm{TM}}$} & \multicolumn{3}{|c|}{ Online } & \multicolumn{3}{|c|}{ Restaurant } \\
\hline & & 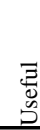 & 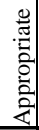 & 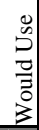 & 寻 & $\begin{array}{l}\text { : } \\
\text { : } \\
0 \\
\text { 言 }\end{array}$ & $\begin{array}{l}\stackrel{0}{0} \\
\overrightarrow{0} \\
0 \\
0 \\
3\end{array}$ & 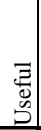 & 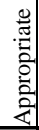 & 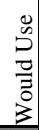 & 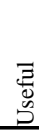 & $\begin{array}{l}\stackrel{0}{0} \\
0 \\
0 \\
0 \\
0\end{array}$ & $\begin{array}{l}\stackrel{\Xi}{0} \\
0 \\
0 \\
0 \\
3\end{array}$ \\
\hline \multirow{3}{*}{$\begin{array}{l}\text { News } \\
\text { Headlines }\end{array}$} & $\mathrm{U}$ & & & & & & & & T & & & & \\
\hline & A &.. & & & & & & & & & & & \\
\hline & $\mathrm{W}$ & . & $\ddot{.}$ & & & & & & & & & & \\
\hline \multirow{3}{*}{ EBay $^{\mathrm{TM}}$} & $\mathrm{U}$ &.. &.. &.. & & & & & - & & & & \\
\hline & A & .. &.. &.. &.. & & & & & & & & \\
\hline & $\mathrm{W}$ & .. &.. &.. &.. &.. & & & & & & & \\
\hline \multirow{3}{*}{$\begin{array}{l}\text { Online } \\
\text { purchases }\end{array}$} & $\mathrm{U}$ &.. &.. & .. & .. &.. &.. & & 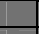 & & & & \\
\hline & A &.. & .. & .. &.. &.. &.. &.. & + & & & & \\
\hline & $\mathrm{W}$ &.. &. &.. &.. &.. &.. & .. &. & & & & \\
\hline \multirow{3}{*}{$\begin{array}{l}\text { Restaurant } \\
\text { Booking }\end{array}$} & $\mathrm{U}$ &.. &.. & &.. &.. & . &.. &.. &.. & & & \\
\hline & A & .. & & &.. &.. & . & .. & . & .. &.. & & \\
\hline & $\mathrm{W}$ & .. &. & & .. &.. &. & .. & .. &. & .. & .. & \\
\hline
\end{tabular}

\section{CONCLUSIONS AND FUTURE WORK}

In summarizing the results, there is a split in opinion about the acceptance of new personalized services. However if new services were to be implemented, users would most desire budgeting advice. Younger users would also tend to accept budgeting advice than older users; they would also like to have news headline information displayed at self-service kiosks.

No overwhelming support exists for using personal information in providing new services; however the majority of users agree that the use of personal information can improve security. Users see avatars as both not suitable and not preferred as a choice of interface, however if an avatar condition was used, most users would not find this detrimental to their perception of the transaction as secure, trustworthy and controllable. A choice between formal and informal avatars favours the informal.

A more detailed examination of the results shows that age correlates with some aspects of acceptance for most new services, suggesting that the sample of younger users is responsible for a large element of those accepting new services. However it is also clear that age is not the only factor, as age shows no correlation with acceptance of online purchases, yet the general level of acceptance for this service shows a similar split. The general correlation of all services with each other also indicates that there is a sample of participants who are willing to accept all new services. Therefore this indicates that from the sample used, a split on opinion is evident and not based solely upon age. It is interesting to note the sample used, a university sample is predominantly university employees and staff who may be expected to have a higher incidence of technology experience. Therefore further investigation of occupation difference was conducted. Chi Squared test investigated differences between occupation groups and new service acceptance. Significant differences were only found for willingness to use news headline and budget advice, indicating a higher proportion of student participants accepting these services. Interestingly professionals were again split between accepting and rejecting news headlines and slightly in favor of budgeting advice suggesting that a split in opinion is not a direct result of occupation differences.

Further examination is warranted to investigate reasons behind the apparent split in user opinion of acceptance of new services. This split seems to exist irrespective of occupation, with age playing a role in determining a degree of support for acceptance of new services. Potential areas for further study not addressed in this study would be user's familiarity with new technologies and their tendency to personalize other technologies.

\section{ACKNOWLEDGMENTS}

We are to the DTI (Department of Trade and Industry, UK) for their support of this work under the auspices of the KTP (Knowledge Transfer Partnership) initiative. Thanks are also due to Darren Grant for his work in prototype development, Napier University for hosting the experimental work and NCR for provision of the ATM/Kiosk model.

\section{REFERENCES}

[1] Blom, J., Personalization Psychological implications of Personalized User Interfaces. Doctoral Thesis. Department of Psychology. University of York (August 2002)

[2] Reeves, B. and Nass, C. The Media Equation. New York: Cambridge University Press. (1996)

[3] De Angeli, A., Lynch, P., Johnson. G., Personifying the eMarket: A Framework for Social Agents. Proceedings of IFIP INTERACT'01: Human-Computer Interaction (2001) 198-205

[4] Ward, J., Sands, J. and Johnson, G. The Effect of 'Tone of Dialogue' on Users' Interactions with Self-Service. Contemporary Ergonomics. London: Taylor and Frances. (2007)

[5] Briggs, P., Simpson, B. and De Angeli, A. Does personalisation affect trust in online advice? CHI2003 Workshop Designing Personalized User Experiences for eCommerce: Theory, Methods, and Research, Fort Lauderdale, Florida. (April 2003)

[6] Neilsen, J., Personalisation is over rated. Jakob Neilsen's Alertbox, (Oct 1998). http://www.useit.com/alertbox/981004.html

[7] Coventry, L., Johnson, G. and De Angeli, A. Achieving accessibility through personalization. People and Computers XVI - Memorable yet invisible. Proceedings of HCI 2002, London: Springer Verlag (2002)

[8] Costa, B., Ditzion, S., Kschwendt, G., Nogales, J., Schmitt, A. and Wang, J. The 2000 Study of Web-ATMs and Kiosks. The Consumer Proposition. Dove Consulting - Executive summary. (August 2000)

[9] QuestionPro. Online Survey Software. www.questionpro.com 